\title{
Convergence theorems of a general approximation method for common fixed points of a finite family of asymptotically-quasi nonexpansive mappings in Banach spaces
}

\author{
Qiao-Li Donga,*, Songnian He ${ }^{a}$, Bin-Chao Deng ${ }^{b}$ \\ ${ }^{a}$ College of Science, Civil Aviation University of China, Tianjin 300300, China. \\ ${ }^{b}$ Technical economy and management specialty, School of Management, Tianjin University, Tianjin 300072, China. \\ This paper is dedicated to Professor Ljubomir Ćirić \\ Communicated by Professor V. Berinde
}

\begin{abstract}
In this paper, we consider a general iterative scheme to approximate a common fixed point for a finite family of asymptotically quasi-nonexpansive mappings. Several strong and weak convergence results are presented in Banach spaces and an finite family of asymptotically quasi-nonexpansive mappings is constructed. Our results generalize and extend many known results in the current literature.(c)2012 NGA. All rights reserved.
\end{abstract}

Keywords: Modified Mann and Ishikawa iterations, Asymptotically quasi-nonexpansive mappings, Common fixed points, Weak and strong convergence, Uniformly convex Banach spaces.

2010 MSC: 47H05, 47H07, 47H10.

\section{Introduction and Preliminaries}

Let $C$ be a nonempty subset of a real Banach space $X$ and $T$ a selfmapping of $C$. Denote by $F(T)$ the set of fixed points of $T$. Throughout this paper, we assume that $F(T) \neq \emptyset$. The mapping $T$ is said to be

\footnotetext{
${ }^{*}$ Corresponding author

Email addresses: dongqiaoli@ymail.com (Qiao-Li Dong), hesongnian2003@yahoo.com.cn (Songnian He), dbchao1985@yahoo.com.cn (Bin-Chao Deng)
} 
(i) nonexpansive if $\|T x-T y\| \leq\|x-y\|$, for all $x, y \in C$;

(ii) quasi-nonexpansive if $\|T x-p\| \leq\|x-p\|$, for all $x \in C$ and $p \in F(T)$;

(iii) asymptotically nonexpansive if there exists a sequence $\left\{r_{n}\right\}$ in $[0, \infty)$ with $\lim _{n \rightarrow \infty} r_{n}=0$ and $\| T^{n} x-$ $T^{n} y\left\|\leq\left(1+r_{n}\right)\right\| x-y \|$, for all $x, y \in C$ and $n=1,2,3, \ldots$;

(iv) asymptotically quasi-nonexpansive if there exists a sequence $\left\{r_{n}\right\}$ in $[0, \infty)$ with $\lim _{n \rightarrow \infty} r_{n}=0$ and $\left\|T^{n} x-p\right\| \leq\left(1+r_{n}\right)\|x-p\|$, for all $x \in C, p \in F(T)$ and $n=1,2,3, \ldots$;

(v) uniformly $L$-Lipschitzian if there exists constant $L>0$ such that $\left\|T^{n} x-T^{n} y\right\| \leq L\|x-y\|$, for all $x, y \in C$ and $n=1,2,3, \ldots$;

(vi) $(L-\gamma)$ uniform Lipschitz if there are constants $L>0$ and $\gamma>0$ such that $\left\|T^{n} x-T^{n} y\right\| \leq L\|x-y\|^{\gamma}$, for all $x, y \in C$ and $n=1,2,3, \ldots$;

(vii) semi-compact if for a sequence $\left\{x_{n}\right\}$ in $C$ with $\lim _{n \rightarrow \infty}\left\|x_{n}-T x_{n}\right\|=0$, there exists a subsequence $\left\{x_{n_{i}}\right\}$ of $\left\{x_{n}\right\}$ such that $x_{n_{i}} \rightarrow p \in C$.

From the definitions, it is easy to see that,

(i) a nonexpansive mapping must be quasi-nonexpansive and asymptotically nonexpansive;

(ii) an asymptotically nonexpansive mapping is an asymptotically quasi-nonexpansive and uniformly $L$ Lipschitzian;

(iii) a uniformly $L$-Lipschitzian mapping is $(L-1)$ uniform Lipschitz.

Condition (A). Let $C$ be a subset of a normed space $X$. A family of self-mappings $\left\{T_{i}: i=1,2, \ldots, k\right\}$ of $C$ is said to have Condition (A) if there exists a nondecreasing function $f:[0, \infty) \rightarrow[0, \infty)$ with $f(0)=0$ and $f(r)>0$ for all $r \in(0, \infty)$ such that $\left\|x-T_{i} x\right\| \geq f(d(x, F))$ for some $1 \leq i \leq k$ and for all $x \in C$, where $d(x, F)=\inf \left\{\|x-p\|: p \in F=\bigcap_{i=1}^{k} F\left(T_{i}\right)\right\}$.

The map $T: C \rightarrow X$ is said to be demiclosed at 0 if for each sequence $\left\{x_{n}\right\}$ in $C$ converging weakly to $x \in C$ and $T x_{n}$ converging strongly to 0 , we get $T x=0$.

A Banach space $X$ is said to have Opial's property if for each sequence $\left\{x_{n}\right\}$ converging weakly to $x \in C$ and $x \neq y$, we have the condition

$$
\liminf _{n \rightarrow \infty}\left\|x_{n}-x\right\|<\liminf _{n \rightarrow \infty}\left\|x_{n}-y\right\| .
$$

Goebel and Kirk [1] introduced the notion of asymptotically nonexpansive and proved that every asymptotically nonexpansive self-mapping of a nonempty closed bounded and convex subset of a uniformly convex Banach space has a fixed point. Bose [2] studied an iterative scheme for fixed points of asymptotically nonexpansive mappings. Khan and Takahashi [3] used the modified Ishikawa process to approximate common fixed points of two asymptotically nonexpansive mappings.

The problem of finding common fixed points of nonlinear mapping is of practical importance. The wellknown convex feasibility problem reduces to finding a point in the intersection of the fixed point sets of a family of nonexpansive mappings. Many researchers [4-7] are interested in studying approximation method for finding common fixed points of nonlinear mapping.

Sun [7] studied an implicit iterative scheme initiated by Xu and Ori [8] for a finite family of asymptotically quasi-nonexpansive mappings. Shahzad and Udomene [9] proved some convergence theorems for the modified Ishikawa iterative process of two asymptotically quasi-nonexpansive mappings to a common fixed point. Fukhar-ud-din and Khan [10] studied a iterative process with errors to approximate the common fixed points of two asymptotically quasi-nonexpansive mappings. 
Recently, Khan et al. [11] introduced an iterative process for a finite family of mappings as follows: Let $C$ be a convex subset of a Banach space $X$ and $\left\{T_{i}: i=1,2, \ldots, k\right\}$ be a family of self-mappings of $C$. Suppose that $a_{i n} \in[0,1]$ for all $n=1,2,3, \ldots$ and $i=1,2, \ldots, k$. For $x_{1} \in C$, let $\left\{x_{n}\right\}$ be the sequence generated by

$$
\begin{aligned}
x_{n+1} & =\left(1-a_{k n}\right) x_{n}+a_{k n} T_{k}^{n} y_{(k-1) n}, \\
y_{(k-1) n} & =\left(1-a_{(k-1) n}\right) x_{n}+a_{(k-1) n} T_{k-1}^{n} y_{(k-2) n}, \\
y_{(k-2) n} & =\left(1-a_{(k-2) n}\right) x_{n}+a_{(k-2) n} T_{k-2}^{n} y_{(k-3) n} \\
& \vdots \\
y_{2 n} & =\left(1-a_{2 n}\right) x_{n}+a_{2 n} T_{2}^{n} y_{1 n}, \\
y_{1 n} & =\left(1-a_{1 n}\right) x_{n}+a_{1 n} T_{1}^{n} y_{0 n},
\end{aligned}
$$

where $y_{0 n}=x_{n}$ for all $n$. The iterative process (1.1) is the generalized form of the modified Mann (one-step) iterative process by Schu [12], the modified Ishikawa (two-step) iterative process by Tan and Xu [13], and the three-step iterative process by Xu and Noor [14].

Very recently, Kettapun et al. [15] introduced an iterative process for a finite family of mappings as follows: for $x_{1} \in C$, let $\left\{x_{n}\right\}$ be the sequence generated by

$$
\begin{aligned}
x_{n+1} & =\left(1-a_{k n}\right) y_{(k-1) n}+a_{k n} T_{k}^{n} y_{(k-1) n}, \\
y_{(k-1) n} & =\left(1-a_{(k-1) n}\right) y_{(k-2) n}+a_{(k-1) n} T_{k-1}^{n} y_{(k-2) n}, \\
y_{(k-2) n} & =\left(1-a_{(k-2) n}\right) y_{(k-3) n}+a_{(k-2) n} T_{k-2}^{n} y_{(k-3) n}, \\
& \vdots \\
y_{2 n} & =\left(1-a_{2 n}\right) y_{1 n}+a_{2 n} T_{2}^{n} y_{1 n}, \\
y_{1 n} & =\left(1-a_{1 n}\right) y_{0 n}+a_{1 n} T_{1}^{n} y_{0 n},
\end{aligned}
$$

where $y_{0 n}=x_{n}$ for all $n$.

Motivated by Khan et al. [11] and Kettapun et al. [15], we introduce a new iterative scheme for finding a common fixed point of a finite family of asymptotically quasi-nonexpansive mappings as follow: for $x_{1} \in C$, let $\left\{x_{n}\right\}$ be the sequence generated by

$$
\begin{aligned}
x_{n+1}= & a_{k n} x_{n}+b_{k n} y_{(k-1) n}+c_{k n} T_{k}^{n} y_{(k-1) n}, \\
y_{(k-1) n}= & a_{(k-1) n} x_{n}+b_{(k-1) n} y_{(k-2) n}+c_{(k-1) n} T_{k-1}^{n} y_{(k-2) n}, \\
y_{(k-2) n}= & a_{(k-2) n} x_{n}+b_{(k-2) n} y_{(k-3) n}+c_{(k-2) n} T_{k-2}^{n} y_{(k-3) n}, \\
& \vdots \\
y_{2 n}= & a_{2 n} x_{n}+b_{2 n} y_{1 n}+c_{2 n} T_{2}^{n} y_{1 n}, \\
y_{1 n}= & a_{1 n} x_{n}+b_{1 n} y_{0 n}+c_{1 n} T_{1}^{n} y_{0 n},
\end{aligned}
$$

where $y_{0 n}=x_{n},\left(a_{(i) n}, b_{(i) n}, c_{(i) n}\right) \in I \times I \times I, I=[0,1]$ and $a_{(i) n}+b_{(i) n}+c_{(i) n}=1$, for all $n=1,2,3, \ldots$ and $i=1,2, \ldots, k$.

The aim of this paper is to obtain some strong and weak convergence results for the iterative process (1.3) of a finite family of asymptotically quasi-nonexpansive mappings in Banach spaces.

We need the following useful known lemmas for the development of our convergence results.

Lemma 1.1. (Cf. [7, Lemma 2.2]). Let the sequences $\left\{a_{n}\right\}$ and $\left\{\delta_{n}\right\}$ of real numbers satisfy:

$$
a_{n+1} \leq\left(1+\delta_{n}\right) a_{n}, \quad \text { where } a_{n} \geq 0, \delta_{n} \geq 0 \text { for all } n=1,2,3, \ldots,
$$

and $\sum_{n=1}^{\infty} \delta_{n}<\infty$. Then

(i) $\lim _{n \rightarrow \infty} a_{n}$ exists;

(ii) if $\liminf _{n \rightarrow \infty} a_{n}=0$, then $\lim _{n \rightarrow \infty} a_{n}=0$.

Lemma 1.2. (See $[13$ Lemma 1.3]). Let $X$ be a uniformly convex Banach space. Assume that $0<b \leq$ $t_{n} \leq c<1, n=1,2,3, \ldots$. Let the sequences $\left\{x_{n}\right\}$ and $\left\{y_{n}\right\}$ in $X$ be such that $\lim _{\sup _{n \rightarrow \infty}}\left\|x_{n}\right\| \leq a$, $\lim \sup _{n \rightarrow \infty}\left\|y_{n}\right\| \leq a$ and $\lim _{n \rightarrow \infty}\left\|t_{n} x_{n}+\left(1-t_{n}\right) y_{n}\right\|=a$, where $a \geq 0$. Then $\lim _{n \rightarrow \infty}\left\|x_{n}-y_{n}\right\|=0$. 


\section{Convergence in Banach spaces}

The aim of this section is to establish the strong convergence of the iterative scheme 1.3$)$ to converge to a common fixed point of a finite family of asymptotically quasi-nonexpansive mappings in a Banach space under some appropriate conditions.

Lemma 2.1. Let $C$ be a nonempty closed convex subset of a real Banach space $X$, and $\left\{T_{i}: i=1,2, \ldots, k\right\}$ be a family of asymtotically quasi-nonexpansive self-mappings of $C$, i.e., $\left\|T_{i}^{n} x-p_{i}\right\| \leq\left(1+r_{i n}\right)\left\|x-p_{i}\right\|$, for all $x \in C$ and $p_{i} \in F\left(T_{i}\right), i=1,2, \ldots, k$. Let $\left(a_{(i) n}, b_{(i) n}, c_{(i) n}\right) \in I \times I \times I$, where $I=[0,1]$ and $a_{(i) n}+b_{(i) n}+c_{(i) n}=1$, for all $n=1,2,3, \ldots$ and $i=1,2, \ldots, k$. Suppose that $F=\bigcap_{i=1}^{k} F\left(T_{i}\right) \neq \emptyset, x_{1} \in C$, and the iterative sequence $\left\{x_{n}\right\}$ is defined by 1.3). Then for $p \in F$, we get

(i) $\left\|T_{i}^{n} y_{(i-1) n}-p\right\| \leq\left(1+r_{n}\right)\left\|y_{(i-1) n}-p\right\|$, for all $i=1,2, \ldots, k$;

(ii) $\left\|y_{\text {in }}-p\right\| \leq\left(1+r_{n}\right)^{i}\left\|x_{n}-p\right\|$, for $i=1,2, \ldots, k-1$;

(iii) $\left\|x_{n+1}-p\right\| \leq\left(1+\delta_{n}\right)\left\|x_{n}-p\right\|$;

(iv) if $\sum_{n=1}^{\infty} r_{n}<\infty, \lim _{n \rightarrow \infty}\left\|x_{n}-p\right\|$ exists,

where $r_{n}=\max _{1 \leq i \leq k}\left\{r_{i n}\right\}$ and $\delta_{n}=\sum_{i=1}^{k}(k i) r_{n}^{i}$.

Proof. Let $p \in F$.

(i) For $i=1,2, \ldots, k$, we have

$$
\left\|T_{i}^{n} y_{(i-1) n}-p\right\| \leq\left(1+r_{n}\right)\left\|y_{(i-1) n}-p\right\| .
$$

(ii) Set $y_{k n}=x_{n+1}$. Using part (i), we obtain

$$
\begin{aligned}
\left\|y_{1 n}-p\right\| & =\left\|a_{1 n} x_{n}+b_{1 n} x_{n}+c_{1 n} T_{1}^{n} x_{n}-p\right\| \\
& \leq a_{1 n}\left\|x_{n}-p\right\|+b_{1 n}\left\|x_{n}-p\right\|+c_{1 n}\left\|T_{1}^{n} x_{n}-p\right\| \\
& \leq\left(1-c_{1 n}\right)\left\|x_{n}-p\right\|+c_{1 n}\left(1+\gamma_{n}\right)\left\|x_{n}-p\right\| \\
& \leq\left(1+\gamma_{n}\right)\left\|x_{n}-p\right\| .
\end{aligned}
$$

Assume that $\left\|y_{j n}-p\right\| \leq\left(1+\gamma_{n}\right)^{j}\left\|x_{n}-p\right\|$ holds for some $1 \leq j \leq k-1$. We have

$$
\begin{aligned}
\left\|y_{(j+1) n}-p\right\| & =\left\|a_{(j+1) n} x_{n}+b_{(j+1) n} y_{j n}+c_{(j+1) n} T_{j+1}^{n} y_{j n}-p\right\| \\
& \leq a_{(j+1) n}\left\|x_{n}-p\right\|+b_{(j+1) n}\left\|y_{j n}-p\right\|+c_{(j+1) n}\left\|T_{j+1}^{n} y_{j n}-p\right\| \\
& \leq a_{(j+1) n}\left\|x_{n}-p\right\|+b_{(j+1) n}\left\|y_{j n}-p\right\|+c_{(j+1) n}\left(1+r_{n}\right)\left\|y_{j n}-p\right\| \\
& \leq a_{(j+1) n}\left\|x_{n}-p\right\|+\left(1-a_{(j+1) n}\right)\left(1+r_{n}\right)\left\|y_{j n}-p\right\| \\
& \leq a_{(j+1) n}\left(1+r_{n}\right)^{j+1}\left\|x_{n}-p\right\|+\left(1-a_{(j+1) n}\right)\left(1+r_{n}\right)^{j+1}\left\|x_{n}-p\right\| \\
& \leq\left(1+r_{n}\right)^{j+1}\left\|x_{n}-p\right\| .
\end{aligned}
$$

Thus, by induction, we have

$$
\left\|y_{\text {in }}-p\right\| \leq\left(1+r_{n}\right)^{i}\left\|x_{n}-p\right\|, \quad \text { for } i=1,2, \ldots, k .
$$

(iii) By part part (ii), we get

$$
\begin{aligned}
\left\|x_{n+1}-p\right\| & =\left\|y_{k n}-p\right\| \leq\left(1+r_{n}\right)^{k}\left\|x_{n}-p\right\| \\
& =\left(1+\delta_{n}\right)\left\|x_{n}-p\right\| .
\end{aligned}
$$

(iv) By (iii), we have $\left\|x_{n+1}-p\right\| \leq\left(1+\delta_{n}\right)\left\|x_{n}-p\right\|$. From $\sum_{n=1}^{\infty} r_{n}<\infty$, we also have $\sum_{n=1}^{\infty} r_{n}^{i}<\infty$, for $i=1,2, \ldots, k$. It follows that $\sum_{n=1}^{\infty} \delta_{n}=\sum_{n=1}^{\infty}\left[\sum_{i=1}^{k}(k i) r_{n}^{i}\right]=\sum_{i=1}^{k}\left[(k i) \sum_{n=1}^{\infty} r_{n}^{i}\right]<\infty$. By Lemma 1 , we get $\lim _{n \rightarrow \infty}\left\|x_{n}-p\right\|$ exists. 
Theorem 2.2. Let $C$ be a nonempty closed convex subset of a real Banach space $X$, and $\left\{T_{i}: i=1,2, \ldots, k\right\}$ be a family of asymtotically quasi-nonexpansive self-mappings of $C$, i.e., $\left\|T_{i}^{n} x-p_{i}\right\| \leq\left(1+r_{i n}\right)\left\|x-p_{i}\right\|$, for all $x \in C$ and $p_{i} \in F\left(T_{i}\right), i=1,2, \ldots, k$. Suppose that $F=\bigcap_{i=1}^{k} F\left(T_{i}\right) \neq \emptyset, x_{1} \in C$, and the iterative sequence $\left\{x_{n}\right\}$ is defined by (1.3). Let $\left(a_{(i) n}, b_{(i) n}, c_{(i) n}\right) \in I \times I \times I$, where $I=[0,1]$ and $a_{(i) n}+b_{(i) n}+c_{(i) n}=1$, for all $n=1,2,3, \ldots$ and $i=1,2, \ldots, k$. Assume that $\sum_{n=1}^{\infty} r_{n}<\infty$, where $r_{n}=\max _{1 \leq i \leq k}\left\{r_{i n}\right\}$. Then $\left\{x_{n}\right\}$ converges strongly to a common fixed point of the family of mappings if and only if $\liminf _{n \rightarrow \infty} d\left(x_{n}, F\right)=0$, where $d(x, F)=\inf _{p \in F}\|x-p\|$.

Proof. Since the necessity is obvious, we will only prove the sufficiency. Take the infimum over $F$ in $(2.2)$, we have

$$
d\left(x_{n+1}, F\right) \leq\left(1+\delta_{n}\right) d\left(x_{n}, F\right) .
$$

By $\sum_{n=1}^{\infty} \delta_{n}<\infty, \liminf _{n \rightarrow \infty} d\left(x_{n}, F\right)=0$, and Lemma 1, we get that $\lim _{n \rightarrow \infty} d\left(x_{n}, F\right)=0$.

Next, we show that $\left\{x_{n}\right\}$ is a Cauchy sequence in $C$. Let $p \in F$. By Lemma 3(iv), $\lim _{n \rightarrow \infty}\left\|x_{n}-p\right\|$ exists and hence $\left\{\left\|x_{n}-p\right\|\right\}$ is bounded. Set $M=\sup _{n \geq 1}\left\{\left\|x_{n}-p\right\|\right\}$. From Lemma 3(iii), we get

$$
\left\|x_{n+1}-p\right\| \leq\left\|x_{n}-p\right\|+M \delta_{n}
$$

Thus, for positive integers $m$ and $n$, we have

$$
\begin{aligned}
\left\|x_{n+m}-p\right\| \leq & \left\|x_{n+m-1}-p\right\|+M \delta_{n+m-1} \\
\leq & \left\|x_{n+m-2}-p\right\|+M\left(\delta_{n+m-1}+\delta_{n+m-2}\right) \\
& \vdots \\
\leq & \left\|x_{n}-p\right\|+M \sum_{i=n}^{n+m-1} \delta_{i} .
\end{aligned}
$$

Therefore, for any $p \in F$, we have

$$
\begin{aligned}
\left\|x_{n+m}-x_{n}\right\| & \leq\left\|x_{n+m}-p\right\|+\left\|x_{n}-p\right\| \\
& \leq 2\left\|x_{n}-p\right\|+M \sum_{i=n}^{n+m-1} \delta_{i} .
\end{aligned}
$$

Hence,

$$
\left\|x_{n+m}-x_{n}\right\| \leq 2 d\left(x_{n}, F\right)+M \sum_{i=n}^{n+m-1} \delta_{i} .
$$

By $\lim _{n \rightarrow \infty} d\left(x_{n}, F\right)=0$ and $\sum_{n=1}^{\infty} \delta_{n}<\infty$, we get that $\left\{x_{n}\right\}$ is a Cauchy sequence in $X$. Since $X$ is complete, $x_{n} \rightarrow q \in X$. Actually, $q \in C$ because $\left\{x_{n}\right\} \subset C$ and $C$ is a closed subset of $X$. Next we show that $q \in F$. Since $F\left(T_{i}\right)$ is a closed subset in $C$ for all $i=1,2, \ldots, k$, so is $F=\bigcap_{i=1}^{k} F\left(T_{i}\right)$. From the continuity of $d(x, F)$ with $d\left(x_{n}, F\right) \rightarrow 0$ and $x_{n} \rightarrow q$ as $n \rightarrow \infty$, we get $d(q, F)=0$ and then $q \in F$. Therefore, the proof is complete.

Since any asymptotically nonexpansive mapping is asymptotically quasi-nonexpansive, the next corollary is obtained immediately from Theorem 4.

Corollary 2.3. Let $C$ be a nonempty closed convex subset of a real Banach space $X$, and $\left\{T_{i}: i=1,2, \ldots, k\right\}$ be a family of asymptotically nonexpansive self-mappings of $C$, i.e., $\left\|T_{i}^{n} x-T_{i}^{n} y\right\| \leq\left(1+r_{i n}\right)\|x-y\|$, for all $x, y \in C, i=1,2, \ldots, k$. Let $\left(a_{(i) n}, b_{(i) n}, c_{(i) n}\right) \in I \times I \times I$, where $I=[0,1]$ and $a_{(i) n}+b_{(i) n}+c_{(i) n}=1$, for all $n=1,2,3, \ldots$ and $i=1,2, \ldots, k$. Suppose that $F=\bigcap_{i=1}^{k} F\left(T_{i}\right) \neq \emptyset, x_{1} \in C$, and the iterative sequence $\left\{x_{n}\right\}$ is defined by (1.3). Then $\left\{x_{n}\right\}$ converges strongly to a common fixed point of the family of mappings if and only if $\liminf \operatorname{in}_{n \rightarrow \infty} d\left(x_{n}, F\right)=0$, where $d(x, F)=\inf _{p \in F}\|x-p\|$. 


\section{Results in uniformly convex Banach spaces}

In this section, we establish some weak and strong convergence results for the iterative scheme (1.3) by removing the condition $\lim \inf _{n \rightarrow \infty} d\left(x_{n}, F\right)=0$ from the results obtained in Section 3. Instead, we consider the class of $(L-\gamma)$ uniform Lipschitz and asymptotically quasi-nonexpansive mappings on a uniformly convex Banach space.

Lemma 3.1. Let $C$ be a nonempty closed convex subset of an uniformly convex real Banach space $X$, and $\left\{T_{i}: i=1,2, \ldots, k\right\}$ be a family of $\left(L-\gamma_{i}\right)$ uniform Lipschitz and asymtotically quasi-nonexpansive selfmappings of $C$, i.e., $\left\|T_{i}^{n} x-T_{i}^{n} y\right\| \leq L\left\|x-p_{i}\right\|^{\gamma_{i}}$, and $\left\|T_{i}^{n} x-p_{i}\right\| \leq\left(1+r_{i n}\right)\left\|x-p_{i}\right\|$, for all $x, y \in C$ and $p_{i} \in F\left(T_{i}\right), i=1,2, \ldots, k$. Suppose that $F=\bigcap_{i=1}^{k} F\left(T_{i}\right) \neq \emptyset, x_{1} \in C$, and the iterative sequence $\left\{x_{n}\right\}$ is defined by 1.3). For $n=1,2,3, \ldots$ and $i=1,2, \ldots, k$, let $\left(a_{(i) n}, b_{(i) n}, c_{(i) n}\right) \in I \times I \times I$, where $I=[0,1]$ and $a_{(i) n}+b_{(i) n}+c_{(i) n}=1, a_{i n} \in[\delta, 1-\delta]$ for some $\delta \in\left(0, \frac{1}{2}\right)$, and $b_{i n} \in[a, b]$ for some $0<a<b<1$. Assume that $\sum_{n=1}^{\infty} r_{n}<\infty$, where $r_{n}=\max _{1 \leq i \leq k}\left\{r_{i n}\right\}$. Then,

(i) $\lim _{n \rightarrow \infty}\left\|x_{n}-T_{i}^{n} y_{(i-1) n}\right\|=0$, for all $i=1,2, \ldots, k$;

(ii) $\lim _{n \rightarrow \infty}\left\|x_{n}-T_{i} x_{n}\right\|=0$, for all $i=1,2, \ldots, k$.

Proof. (i) Let $p \in F$. By Lemma 3(iv), we obtain that $\lim _{n \rightarrow \infty}\left\|x_{n}-p\right\|$ exists and we then suppose that

$$
\lim _{n \rightarrow \infty}\left\|x_{n}-p\right\|=c
$$

By (3.1) and Lemma 3(ii), we have

$$
\limsup _{n \rightarrow \infty}\left\|y_{i n}-p\right\| \leq c, \quad \text { for } i=1,2, \ldots, k-1 .
$$

We also notice that

$$
\begin{aligned}
\left\|x_{n+1}-p\right\| \leq & \left\|a_{k n} x_{n}+b_{k n} y_{(k-1) n}+c_{k n} T_{k}^{n} y_{(k-1) n}-p\right\| \\
\leq & a_{k n}\left\|x_{n}-p\right\|+b_{k n}\left\|y_{(k-1) n}-p\right\|+c_{k n}\left(1+r_{n}\right)\left\|y_{(k-1) n}-p\right\| \\
\leq & a_{k n}\left\|x_{n}-p\right\|+\left(1-a_{k n}\right)\left(1+r_{n}\right)\left\|y_{(k-1) n}-p\right\| \\
& \quad \vdots \\
\leq & \quad\left(1-\left(1-a_{k n}\right)\left(1-a_{(k-1) n}\right) \cdots\left(1-a_{(i+1) n}\right)\right)\left(1+r_{n}\right)^{k-i}\left\|x_{n}-p\right\| \\
& \quad+\left(1-a_{k n}\right)\left(1-a_{(k-1) n}\right) \cdots\left(1-a_{(i+1) n}\right)\left(1+r_{n}\right)^{k-i}\left\|y_{i n}-p\right\|,
\end{aligned}
$$

which implies

$$
\begin{aligned}
\left\|x_{n}-p\right\| \leq & \frac{\left\|x_{n}-p\right\|}{\left(1-a_{k n}\right)\left(1-a_{(k-1) n}\right) \cdots\left(1-a_{(i+1) n}\right)} \\
& -\frac{\left\|x_{n+1}-p\right\|}{\left(1-a_{k n}\right)\left(1-a_{(k-1) n}\right) \cdots\left(1-a_{(i+1) n}\right)\left(1+r_{n}\right)^{k-i}}+\left\|y_{i n}-p\right\| \\
\leq & \frac{\left\|x_{n}-p\right\|\left(1+r_{n}\right)^{k}-\left\|x_{n+1}-p\right\|}{\left(1-a_{k n}\right)\left(1-a_{(k-1) n}\right) \cdots\left(1-a_{(i+1) n}\right)\left(1+r_{n}\right)^{k-i}}+\left\|y_{i n}-p\right\| .
\end{aligned}
$$

Therefore,

$$
\left\|x_{n}-p\right\| \leq \frac{\left\|x_{n}-p\right\|\left(1+r_{n}\right)^{k}-\left\|x_{n+1}-p\right\|}{\delta^{k-i}\left(1+r_{n}\right)^{k-i}}+\left\|y_{i n}-p\right\|
$$

and hence

$$
c \leq \liminf _{n \rightarrow \infty}\left\|y_{i n}-p\right\|, \quad \text { for } i=1,2, \ldots, k-1 .
$$


Combining (3.2) and 3.3), we have

$$
\lim _{n \rightarrow \infty}\left\|y_{i n}-p\right\|=c, \quad \text { for } i=1,2, \ldots, k-1 .
$$

Let $y_{k n}=x_{n+1}$, then we have $\lim _{n \rightarrow \infty}\left\|y_{k n}-p\right\|=\lim _{n \rightarrow \infty}\left\|x_{n+1}-p\right\|=c$. So, we get, for $i=1,2, \ldots, k$,

$$
\begin{aligned}
& \lim _{n \rightarrow \infty}\left\|a_{i n}\left(x_{n}-p\right)+b_{i n}\left(y_{(i-1) n}-p\right)+c_{i n}\left(T_{i}^{n} y_{(i-1) n}-p\right)\right\| \\
= & \lim _{n \rightarrow \infty}\left\|a_{i n}\left(x_{n}-p\right)+\left(1-a_{i n}\right)\left[\frac{b_{i n}}{1-a_{i n}}\left(y_{(i-1) n}-p\right)+\frac{c_{i n}}{1-a_{i n}}\left(T_{i}^{n} y_{(i-1) n}-p\right)\right]\right\| \\
= & \lim _{n \rightarrow \infty}\left\|c_{i n}\left(T_{i}^{n} y_{(i-1) n}-p\right)+\left(1-c_{i n}\right)\left[\frac{a_{i n}}{1-c_{i n}}\left(x_{n}-p\right)+\frac{b_{i n}}{1-c_{i n}}\left(y_{(i-1) n}-p\right)\right]\right\| \\
= & c .
\end{aligned}
$$

Also, from Lemma 3(i) and 3.2, we obtain

$$
\limsup _{n \rightarrow \infty}\left\|T_{i}^{n} y_{(i-1) n}-p\right\| \leq c, \quad \text { for } i=1,2, \ldots, k .
$$

Thus, we can get, for $i=1,2, \ldots, k$,

$$
\begin{aligned}
& \limsup _{n \rightarrow \infty}\left\|\frac{b_{i n}}{1-a_{i n}}\left(y_{(i-1) n}-p\right)+\frac{c_{i n}}{1-a_{i n}}\left(T_{i}^{n} y_{(i-1) n}-p\right)\right\| \\
\leq & \limsup _{n \rightarrow \infty}\left[\frac{b_{i n}}{1-a_{i n}}\left\|y_{(i-1) n}-p\right\|+\frac{c_{i n}}{1-a_{i n}}\left\|T_{i}^{n} y_{(i-1) n}-p\right\|\right] \\
\leq & c
\end{aligned}
$$

and

$$
\begin{aligned}
& \limsup _{n \rightarrow \infty}\left\|\frac{a_{i n}}{1-c_{i n}}\left(x_{n}-p\right)+\frac{b_{i n}}{1-c_{i n}}\left(y_{(i-1) n}-p\right)\right\| \\
\leq & \limsup _{n \rightarrow \infty}\left[\frac{a_{i n}}{1-c_{i n}}\left\|x_{n}-p\right\|+\frac{b_{i n}}{1-c_{i n}}\left\|y_{(i-1) n}-p\right\|\right] \\
\leq & c .
\end{aligned}
$$

By Lemma 2, we obtain, for $i=1,2, \ldots, k$,

$$
\lim _{n \rightarrow \infty} \frac{1}{1-a_{i n}}\left\|\left(1-a_{i n}\right) x_{n}-\left(b_{i n} y_{(i-1) n}+c_{i n} T_{i}^{n} y_{(i-1) n}\right)\right\|=0,
$$

and

$$
\lim _{n \rightarrow \infty} \frac{1}{1-c_{i n}}\left\|\left(1-c_{i n}\right) T_{i}^{n} y_{(i-1) n}-\left(a_{i n} x_{n}+b_{i n} y_{(i-1) n}\right)\right\|=0 .
$$

So, we have, for $i=1,2, \ldots, k$,

$$
\begin{aligned}
& \lim _{n \rightarrow \infty}\left\|x_{n}-y_{i n}\right\| \\
= & \lim _{n \rightarrow \infty}\left\|x_{n}-\left(b_{i n} y_{(i-1) n}+a_{i n} x_{n}+c_{i n} T_{i}^{n} y_{(i-1) n}\right)\right\| \\
= & \left(1-a_{i n}\right) \frac{1}{1-a_{i n}}\left\|\left(1-a_{i n}\right) x_{n}-\left(b_{i n} y_{(i-1) n}+c_{i n} T_{i}^{n} y_{(i-1) n}\right)\right\| \\
= & 0,
\end{aligned}
$$

and

$$
\begin{aligned}
& \lim _{n \rightarrow \infty}\left\|T_{i}^{n} y_{(i-1) n}-y_{i n}\right\| \\
= & \lim _{n \rightarrow \infty}\left\|T_{i}^{n} y_{(i-1) n}-\left(a_{i n} x_{n}+b_{i n} y_{(i-1) n}+c_{i n} T_{i}^{n} y_{(i-1) n}\right)\right\| \\
= & \left(1-c_{i n}\right) \frac{1}{1-c_{i n}}\left\|\left(1-c_{i n}\right) T_{i}^{n} y_{(i-1) n}-\left(a_{i n} x_{n}+b_{i n} y_{(i-1) n}\right)\right\| \\
= & 0 .
\end{aligned}
$$

Combining (3.6)-(3.7), we can get

$$
\lim _{n \rightarrow \infty}\left\|x_{n}-T_{i}^{n} y_{(i-1) n}\right\|=0, \quad \text { for } i=1,2, \ldots, k .
$$


(ii) From part (i), for $i=1$, we have

$$
\lim _{n \rightarrow \infty}\left\|T_{1}^{n} x_{n}-x_{n}\right\|=0 .
$$

For $i=2,3, \ldots, k$, we get

$$
\begin{aligned}
\lim _{n \rightarrow \infty}\left\|T_{i}^{n} x_{n}-x_{n}\right\| & \leq\left\|T_{i}^{n} x_{n}-T_{i}^{n} y_{(i-1) n}\right\|+\left\|T_{i}^{n} y_{(i-1) n}-x_{n}\right\| \\
& \leq L\left\|x_{n}-y_{(i-1) n}\right\|^{\gamma_{i}}+\left\|T_{i}^{n} y_{(i-1) n}-x_{n}\right\| .
\end{aligned}
$$

By part (i) and (3.6), we conclude that

$$
\lim _{n \rightarrow \infty}\left\|T_{i}^{n} x_{n}-x_{n}\right\|=0, \quad \text { for } i=1,2, \ldots, k .
$$

From (1.3), we have

$$
\left\|x_{n+1}-x_{n}\right\| \leq b_{k n}\left\|y_{(k-1) n}-x_{n}\right\|+c_{k n}\left\|T_{k}^{n} y_{(k-1) n}-x_{n}\right\| .
$$

From 3.6 and 3.8 ,

$$
\lim _{n \rightarrow \infty}\left\|x_{n+1}-x_{n}\right\|=0
$$

For $i=1,2, \ldots, k$, we have

$$
\begin{gathered}
\left\|x_{n}-T_{i} x_{n}\right\| \leq\left\|x_{n}-x_{n+1}\right\|+\left\|x_{n+1}-T_{i}^{n+1} x_{n+1}\right\|+\left\|T_{i}^{n+1} x_{n+1}-T_{i}^{n+1} x_{n}\right\| \\
\quad+\left\|T_{i}^{n+1} x_{n}-T_{i} x_{n}\right\| \\
\leq\left\|x_{n}-x_{n+1}\right\|+\left\|x_{n+1}-T_{i}^{n+1} x_{n+1}\right\|+L\left\|x_{n+1}-x_{n}\right\|^{\gamma_{i}} \\
\quad+L\left\|T_{i}^{n} x_{n}-x_{n}\right\|^{\gamma_{i}} .
\end{gathered}
$$

Using (3.10) and (3.11), we obtain

$$
\lim _{n \rightarrow \infty}\left\|x_{n}-T_{i} x_{n}\right\|=0, \quad \text { for } i=1,2, \ldots, k .
$$

Theorem 3.2. Under the hypotheses of Lemma 6, suppose that $\left\{T_{i}: i=1,2, \ldots, k\right\}$ satisfies Condition (A). Then $\left\{x_{n}\right\}$ converges strongly to a common fixed point of the family of mappings.

Proof. By using Condition (A), there exists a nondecreasing function $f:[0, \infty) \rightarrow[0, \infty)$ with $f(0)=0$ and $f(r)>0$ for all $r \in(0, \infty)$ such that

$$
\left\|x_{n}-T_{j} x_{n}\right\| \geq f\left(d\left(x_{n}, F\right)\right)
$$

for some $1 \leq j \leq k$. From Lemma 6 (ii), we have

$$
\lim _{n \rightarrow \infty}\left\|x_{n}-T_{i} x_{n}\right\|=0, \quad \text { for } i=1,2, \ldots, k .
$$

So, we get $\lim _{n \rightarrow \infty} f\left(d\left(x_{n}, F\right)\right)=0$ which implies

$$
\lim _{n \rightarrow \infty} d\left(x_{n}, F\right)=0 .
$$

By Theorem 4, we conclude that $\left\{x_{n}\right\}$ converges strongly to a point $p \in F$.

Theorem 3.3. Under the hypotheses of Lemma 6 , assume that $T_{j}^{m}$ is semi-compact for some positive integers $m$ and $1 \leq j \leq k$. Then $\left\{x_{n}\right\}$ converges strongly to a common fixed point of the family $\left\{T_{i}: i=\right.$ $1,2, \ldots, k\}$. 
Proof. Suppose that $T_{j}^{m}$ is semi-compact for some positive integers $m$ and $1 \leq j \leq k$. We have

$$
\begin{aligned}
\left\|T_{j}^{m} x_{n}-x_{n}\right\| \leq & \left\|T_{j}^{m} x_{n}-T_{j}^{m-1} x_{n}\right\|+\left\|T_{j}^{m-1} x_{n}-T_{j}^{m-2} x_{n}\right\|+\cdots+\left\|T_{j}^{2} x_{n}-T_{j} x_{n}\right\| \\
& \quad+\left\|T_{j} x_{n}-x_{n}\right\| \\
\leq & (m-1) L\left\|T_{j} x_{n}-x_{n}\right\|^{\gamma_{j}}+\left\|T_{j} x_{n}-x_{n}\right\| .
\end{aligned}
$$

Then, by Lemma 6(ii), we get $\left\|T_{j}^{m} x_{n}-x_{n}\right\| \rightarrow 0$ as $n \rightarrow \infty$. Since $\left\{x_{n}\right\}$ is bounded and $T_{j}^{m}$ is semi-compact, there exists a subsequence $\left\{x_{n_{l}}\right\}$ of $\left\{x_{n}\right\}$ such that $x_{n_{l}} \rightarrow q \in C$ as $l \rightarrow \infty$.

By continuity of $T_{i}$ and Lemma 6(ii), we obtain

$$
\left\|q-T_{i} q\right\|=\lim _{l \rightarrow \infty}\left\|x_{n_{l}}-T_{i} x_{n_{l}}\right\|=0, \quad \text { for all } j=1,2, \ldots, k .
$$

Therefore, $q \in F$, and $\liminf _{n \rightarrow \infty} d\left(x_{n}, F\right)=0$ and then Theorem 4 implies that $\left\{x_{n}\right\}$ converges strongly to a common fixed point $q$ of the family $\left\{T_{i}: i=1,2, \ldots, k\right\}$.

Theorem 8 is very useful in the case that one of $T_{i}: i=1,2, \ldots, k$, is semi-compact.

Theorem 3.4. Let $C$ be a nonempty closed convex subset of an uniformly convex real Banach space $X$ satisfying the Opial property, and $\left\{T_{i}: i=1,2, \ldots, k\right\}$ be a family of $\left(L-\gamma_{i}\right)$ uniform Lipschitz and asymtotically quasi-nonexpansive self-mappings of $C$, i.e., $\left\|T_{i}^{n} x-T_{i}^{n} y\right\| \leq L\left\|x-p_{i}\right\|^{\gamma_{i}}$, and $\left\|T_{i}^{n} x-p_{i}\right\| \leq$ $\left(1+r_{i n}\right)\left\|x-p_{i}\right\|$, for all $x, y \in C$ and $p_{i} \in F\left(T_{i}\right), i=1,2, \ldots, k$. Suppose that $F=\bigcap_{i=1}^{k} F\left(T_{i}\right) \neq \emptyset$, $x_{1} \in C$, and the iterative sequence $\left\{x_{n}\right\}$ is defined by 1.3). For $n=1,2,3, \ldots$ and $i=1,2, \ldots, k$, let $\left(a_{(i) n}, b_{(i) n}, c_{(i) n}\right) \in I \times I \times I$, where $I=[0,1]$ and $a_{(i) n}+b_{(i) n}+c_{(i) n}=1, a_{i n} \in[\delta, 1-\delta]$ for some $\delta \in\left(0, \frac{1}{2}\right)$, and $b_{\text {in }} \in[a, b]$ for some $0<a<b<1$. Assume that $\sum_{n=1}^{\infty} r_{n}<\infty$, where $r_{n}=\max _{1 \leq i \leq k}\left\{r_{i n}\right\}$. If $I-T_{i}$, $i=1,2, \ldots, k$, is demiclosed at 0 , then $\left\{x_{n}\right\}$ converges weakly to a common fixed point of the family of mappings.

Proof. Let $p \in F$. By Lemma 3(iv), we get $\lim _{n \rightarrow \infty}\left\|x_{n}-p\right\|$ exists. Then we follow the proof of Theorem 3.2 by Khan et al. [1] until we can conclude that $\left\{x_{n}\right\}$ converges weakly to a common fixed point $p \in F$.

Remark 3.5. It is clear that Theorems 4, 7, 8 and 9 can be used for any asymptotically nonexpansive mapping.

\section{An example}

In this section, we will construct an finite family of quasi-nonexpansive mappings satisfying the conditions of Thoerem 7 .

Let $X=l^{2}$ with the norm $\|\cdot\|$ defined by

$$
\|x\|=\sqrt{\sum_{i=1}^{\infty} x_{i}^{2}}, \quad \forall x=\left(x_{1}, x_{2}, \ldots, x_{n}, \ldots\right) \in X,
$$

and $C=\left\{x=\left(x_{1}, x_{2}, \ldots, x_{n}, \ldots\right) \mid x_{1} \leq 0, x_{i} \in R^{1}, i=2,3, \ldots\right\}$. Then it is obvious that $C$ is a nonempty closed convex subset of $X$.

Now, for any $x=\left(x_{1}, x_{2}, \ldots, x_{n}, \ldots\right) \in C$, define an finite family of mappings $T_{i}: C \rightarrow C, i=1,2, \ldots, k$ as follows:

$$
\begin{aligned}
& T_{1}(x)=\left(0,4 x_{1}, 0, \ldots, 0\right), \\
& T_{2}(x)=\left(0,0,4 x_{1}, \ldots, 0\right),
\end{aligned}
$$




$$
\begin{aligned}
& T_{i}(x)=(\underbrace{0, \ldots, 0}_{i}, 4 x_{1}, \ldots, 0), \\
& \vdots \\
& T_{k}(x)=(0, \ldots, 0, \underbrace{4 x_{1}}_{k+1}, \ldots, 0) .
\end{aligned}
$$

It is easy to see that $T_{i}$ is an asymptotically quasi-nonexpansive mapping. In fact, for any $x=\left(x_{1}, x_{2}, \ldots, x_{n}, \ldots\right) \in$ $C$, letting $T_{i}(x)=x$, i.e.

$$
(\underbrace{0, \ldots, 0}_{i}, 4 x_{1}, \ldots, 0)=\left(x_{1}, x_{2}, \ldots, x_{n}, \ldots\right),
$$

we get $F\left(T_{i}\right)=\{0\}$ and

$$
T_{i}^{n}(x)=(0,0,0, \ldots, 0, \ldots), \quad \forall n=2,3, \ldots, \quad i=1,2, \ldots, k .
$$

For $i=1,2, \ldots, k, \forall n \geq 1$, take $r_{i n} \in[0, \infty)$ with $r_{i 1}=3$ and $\lim _{n \rightarrow \infty} r_{i n}=0$, and $\forall p \in F\left(T_{i}\right)$, we have

$$
\begin{aligned}
\left\|T_{i}(x)-p\right\|-\left(1+r_{i 1}\right)\|x-p\| & =\left\|(\underbrace{0, \ldots, 0}_{i}, 4 x_{1}, \ldots, 0)\right\|-(1+3)\left\|\left(x_{1}, x_{2}, \ldots, x_{n}, \cdots\right)\right\| \\
& =-4 x_{1}-4 \sqrt{\sum_{i=1}^{\infty} x_{i}^{2}} \leq 0,
\end{aligned}
$$

and, for all $n=2,3, \ldots$,

$$
\left\|T_{i}^{n}(x)-p\right\|-\left(1+r_{i n}\right)\|x-p\|=0-\left(1+r_{i n}\right)\|x\| \leq 0 .
$$

So $T_{i}, i=1,2, \ldots, k$, is an asymptotically quasi-nonexpansive mapping.

Next we prove the following results :

(i) $T_{i}, i=1, \ldots, k$, is a Lipschitzian mapping.

For $\forall x, y \in C$, we have

$$
\begin{aligned}
\left\|T_{i} x-T_{i} y\right\| & \leq\left\|(\underbrace{0, \ldots, 0}_{i}, 4 x_{1}, \ldots, 0)-(\underbrace{0, \ldots, 0}_{i}, 4 y_{1}, \ldots, 0)\right\| \\
& =4\left|x_{1}-y_{1}\right| \\
& \leq 4\|x-y\|,
\end{aligned}
$$

where $i=1,2, \ldots, k$. This indicates that $T_{i}, i=1,2, \ldots, k$, is a Lipschitzian mapping.

(ii) $T_{i}, i=1, \ldots, k$, satisfies

$$
\left\|T_{i}^{n} x-T_{i}^{n} y\right\| \leq L\|x-y\|^{\gamma}, \quad \forall n \geq 1
$$

where $L=4$ and $\gamma=1$.

For $n \geq 2, \forall x, y \in C$, we have

$$
\begin{aligned}
\left\|T_{i}^{n} x-T_{i}^{n} y\right\| & =\|0-0\| \\
& \leq 4\|x-y\| .
\end{aligned}
$$

Combining the result (i), we obtain (4.1).

(iii) $T_{i}, i=1,2, \ldots, k$, is a semi-compact mapping.

Set a sequence $\left\{x_{n}=\left(x_{n}^{1}, x_{n}^{2}, \ldots, x_{n}^{m}, \ldots\right)\right\}_{n=1}^{\infty}$, then we have, for $i=1,2, \ldots, k$,

$$
\left\|x_{n}-T_{i} x_{n}\right\|=\sqrt{\left(x_{n}^{1}\right)^{2}+\ldots+\left(x_{n}^{i+1}-4 x_{n}^{1}\right)^{2}+\ldots+\left(x_{n}^{m}\right)^{2}+\ldots}
$$

It is easy to see that if $\left\|x_{n}-T_{i} x_{n}\right\| \rightarrow 0$, then we have $x_{n}^{m} \rightarrow 0, m=1,2, \ldots$, which yields $\left\|x_{n}\right\| \rightarrow 0$. Therefore we get the desired result. 


\section{Acknowledgement}

The authors thank the referee for his suggestions regarding the improvement of the paper. This work is partly supported by the NSFC Tianyuan Youth Foundation of Mathematics of China (No. 11126136) and Fundamental Research Funds for the Central Universities (No. ZXH2011C002).

\section{References}

[1] K. Goebel, W.A. Kirk, A fixed point theorem for asymptotically non-expansive mappings, Proc. Amer. Math. Soc., 35 (1972), 171-174. 1

[2] S.C. Bose, Weak convergence to the fixed point of an asymptotically nonexpansive map, Proc. Amer. Math. Soc., 68 (1978), 305-308. 1

[3] S.H. Khan, W. Takahasi, Approximating common fixed points of two asymptotically nonexpanisve mappings, Sci. Math. Jpn., 53 (2001), 143-148. 1

[4] L.C. Ceng, P. Cubiotti, J.C. Yao, Appoximation of common fixed points of families of nonexpansive mappings, Taiwanese J. Math., 12 (2008), 487-500.

[5] Y. Yao, J.C. Yao, H. Zhou, Appoximation methods for common fixed points of infinite countable family of nonexpansive mappings, Comput. Math. Appl. 53(2007)1380-1389.

[6] Q.L. Dong, S. He, F. Su, Strong convergence of an iterative algorithm for an infinite family of strict pseudocontractions in Banach spaces, Appl. Math. Comput., 216 (2010)959-969.

[7] Z.H. Sun, Strong convergence of an implicit iteration process for a finite family of asymptotically quasinonexpansive mappings, J. Math. Anal. Appl., 286 (2003), 351-358. 1

[8] H.K. Xu, R.G. Ori, An implicit iteration process for nonexpansive mappings, Numer. Funct. Anal. Optim., 22 (5-6) (2001), 767-773. 1

[9] N. Shahzad, A. Udomene, Approximating common fixed points of two asymptotically quasi-nonexpanisve mappings in Banach spaces, Fixed Point Theory Appl., (2006) Article ID 18909, 10 pp. 1

[10] H. Fukhar-ud-din, S.H. Khan, Convergence of iterates with errors of asymptotically quasi-nonexpansive mappings and applications, J. Math. Anal. Appl., 328 (2007), 821-829. 1

[11] A.R. Khan, A.A. Domlo, H. Fukhar-ud-din, Common fixed point Noor iteration for a finite family of asymptotically quasi-nonexpansive mappings in Banach spaces, J. Math. Anal. Appl., 341 (2008), 1-11. 1, 1.6

[12] J. Schu, Weak and strong convergence to fixed points of asymptotically nonexpansive mappings, Bull. Austral. Math. Soc., 43 (1991), 153-159. 1

[13] K.K. Tan, H.K. Xu, Fixed point iteration process for asymptotically nonexpansive mappings, Proc. Amer. Math. Soc., 122 (1994), 733-739. 1

[14] B. Xu, M.A. Noor, Fixed-point iterations for asymptotically nonexpansive mappings in Banach spaces, J. Math. Anal. Appl., 267 (2002), 444-453. 1

[15] A. Kettapun, A. Kananthai, S. Suantai, A new approximation method for common fixed points of a finite family of asymptotically quasi-nonexpansive mappings in Banach spaces, Comp. Appl. Math., 60 (2010), 1430-1439. 1. 1 